Artigo

\title{
Desenvolvimento curricular em matemática a partir de projetos integradores: estudo com professoras em formação inicial
}

\section{Curriculum development in Mathematics from integrative projects: a study with teachers in initial training}

\section{Desarrollo curricular en Matemáticas a partir de proyectos integradores: un estudio con profesoras en formación inicial}

\author{
Gilberto Januario ${ }^{1}$ \\ [0000-0003-0024-2096]
}

\begin{abstract}
Resumo
Levar licenciandas a estudar temas do currículo e a experienciar práticas que rompessem com a lógica disciplinar e linear do processo de educar matematicamente motivou a criação de oportunidade para colocá-las no processo de autoria de suas aprendizagens. Neste artigo analisamos 39 projetos integradores concebidos a partir do levantamento de aspectos da realidade local e problemas socais de onde estudantes e escola estão inseridos, para os quais as licenciandas de uma turma do curso de Pedagogia atuaram como autoras. Trata-se de um estudo do tipo análise documental, conduzido pelo objetivo de problematizar o desenvolvimento curricular em Matemática a partir de projetos integradores como prática na formação inicial de professores. A atividade de elaborar esses projetos levou as licenciandas a considerar que a construção do conhecimento implicado em questões e problemas da realidade global ou local envolve estudo, reorganizações e desconstrução da imagem do professor como único detentor do conhecimento. Também indicou a necessidade de se investir em conhecimentos específicos de Matemática e de metodologias de ensino.
\end{abstract}

Palavras-chave: Currículos de Matemática. Integração Curricular. Projeto Integrador. Conhecimento Profissional Docente.

\begin{abstract}
Leading undergraduates to study curriculum themes and experience practices that break with the disciplinary and linear logic of the process of educating mathematically motivated the creation of an opportunity to place them in the process of authoring their learning. In this article, we analyze 39 integrative projects conceived from the survey of aspects of reality and social problems of the local reality where students and school are inserted, for which the undergraduates of a class of the Pedagogy course acted as authors. This is a documental analysis study, conducted with the aim of problematizing the curriculum development in Mathematics from integrative projects as a practice in the initial teacher education. The activity of preparing these projects led the undergraduates to consider that the construction of knowledge involved in issues and problems of global or local reality implies study, reorganization and deconstruction of the teacher's image as the sole holder of knowledge. It also indicated the need to invest in specific knowledge of Mathematics and teaching methodologies.
\end{abstract}

1 januario@ufop.edu.br, Doutor em Educação Matemática, Professor da Universidade Federal de Ouro Preto e Professor do Programa de Pós-Graduação em Educação da Universidade Estadual de Montes Claros, Minas Gerais, Brasil. 
Keywords: Mathematics Curriculum. Curriculum Integration. Integrator Project. Professional Teacher Knowledge.

\section{Resumen}

Liderar a los estudiantes de pregrado a estudiar temas curriculares y experimentar prácticas que rompan con la lógica disciplinar y lineal del proceso de educar matemáticamente motivó la creación de oportunidades para ubicarlos en el proceso de autoría de su aprendizaje. En este artículo se analizan 39 proyectos integradores concebidos a partir del relevamiento de aspectos de la realidad local y problemática social donde se insertan alumnos y escuela, para los cuales actuaron como autores los licenciados de un curso de Pedagogía. Se trata de un estudio de análisis documental, realizado con el objetivo de problematizar el desarrollo curricular en Matemática a partir de proyectos integradores como práctica en la formación inicial docente. La actividad de elaboración de estos proyectos llevó a los estudiantes a considerar que la construcción de saberes involucrados en temas y problemas de la realidad global o local pasa por estudiar, reorganizar y deconstruir la imagen del docente como único poseedor del conocimiento. También indicó la necesidad de invertir en conocimientos específicos de Matemáticas y metodologías de enseñanza.

Palabras claves: Currículo de Matemáticas. Integración Curricular. Proyecto Integrador. Conocimiento Profesional Docente.

\section{0 horizonte para onde olhamos...}

A formação de professores, como lócus de atuação e de pesquisa, é um campo complexo, implicado por diferentes discursos ancorados em variadas concepções e princípios de formação, de currículo, de educação e de escola. A formação inicial, em especial, envolve um conjunto de práticas que buscam levar licenciandos a conhecer, vivenciar, problematizar e refletir os processos formativos, dentre eles, o processo de educar pela Matemática. Nesse contexto, o desenvolvimento curricular tem lugar de significativa importância, considerado como elemento central das práticas de ensino que reverbera os sentidos e significados dos conteúdos e as aprendizagens a serem construídas pelos estudantes.

Os estudos e as discussões feitas no interior do Grupo de Pesquisa Currículos em Educação Matemática (GPCEEM), liderado por nós, convergem para o entendimento que no desenvolvimento curricular estão envolvidos a elaboração de objetivos de ensino; a avaliação e seleção de materiais curriculares; a escolha dos conteúdos, sua organização e abordagem; os materiais de apoio à prática pedagógica; as escolhas de organização de tempos e espaços; a prática de avaliação para a aprendizagem; as estratégias e discursos pedagógicos (JANUARIO, 2020).

O entendimento é que o desenvolvimento curricular, mais que uma prática, constituise como referencial para se pensar e planejar a prática de educar matematicamente, materializando discursos e sentidos do currículo. Assim, tomar o currículo e seu desenvolvimento como tema de estudo na formação inicial de professores que ensinarão Matemática colabora para a constituição da identidade profissional docente (BARBOSA; LOPES, 2020) e para a construção do conhecimento profissional (STEHLING; CONTI, 2020).

O conhecimento sobre o currículo tem sido considerado uma importante categoria de conhecimento que professores precisam desenvolver e mobilizar ao planejar e realizar aulas (SOARES, 2020; JANUARIO, 2020). Embora o conhecimento sobre conteúdos específicos, estratégias de ensino e práticas de avaliação seja fundamental, conhecer sobre currículo, seu 
sentido e forma de estruturação das propostas educativas mostra-se como essencial para se pensar e realizar práticas que rompam com as lógicas tradicional, técnica e disciplinar do conhecimento presente nas práticas de educar matematicamente.

Para se promover uma educação matemática problematizadora de aspectos e questões sociais, é preciso o desenvolvimento curricular integrador do conhecimento; é preciso superar o discurso sobre o currículo e vivenciar o estudo, a reflexão e a elaboração de práticas de ensino baseadas na integração, tendo como princípio uma educação escolar que conceba os estudantes como produtores do conhecimento e, como consequência, do currículo. Naturalmente, oportunizar tal experiência na formação inicial de professores que ensinarão Matemática é uma prática que oportuniza aos licenciandos a construção de conhecimento sobre meios de se desenvolver o currículo considerando os estudantes e seus temas de interesse como ponto de partida das situações de aprendizagem.

Problematizar o desenvolvimento curricular em Matemática a partir de projetos integradores como prática na formação inicial de professores é o que objetivamos nesse artigo. Trata-se de uma discussão a partir de uma proposta formativa no âmbito de uma disciplina ministrada por nós na Licenciatura em Pedagogia da Universidade Federal de Ouro Preto. Nessa disciplina, o estudo sobre integração curricular e o trabalho com projetos se constituiu como referencial para a construção de conhecimentos relativos à Matemática e seu ensino, particularmente, ao considerar os Anos Iniciais do Ensino Fundamental como etapa de escolarização da atuação profissional.

Paralelamente a esse objetivo, intencionamos discutir os professores como agentes de mudanças do desenvolvimento curricular em Matemática e, como consequência, de reformas educacionais. Sobre esse aspecto, Giroux (1997) tem discutido o apelo por mudança no campo da Educação como uma ameaça e desafio aos professores. A ameaça refere-se à desconfiança da capacidade intelectual e moral dos professores da escola pública sobre a formação dos estudantes; o desafio refere-se ao engajamento desses profissionais na melhoria de condições de trabalho e no processo de mostrar à sociedade o papel fundamental que têm na criação de oportunidades de aprendizagem dos estudantes. Nesse sentido, os professores precisam ser entendidos como intelectuais, que desenvolvem e mobilizam conhecimentos socialmente contextualizados, os quais reverberam o processo problematizador de educar matematicamente, em detrimento de um profissional técnico que reproduz determinações curriculares desconexas do mundo-vida de seus estudantes.

\section{Integração curricular em Matemática}

Conforme abordamos na seção anterior, o desenvolvimento curricular envolve diferentes ações, as quais requerem intencionalidade pedagógica e compromisso com princípios político-educacionais. Ao planejar aulas, algumas questões podem servir como ponto de partida para os professores, por exemplo, a Matemática subjacente nas aprendizagens que os estudantes precisam construir deve ser unicamente aquela presente nas prescrições curriculares? Os temas de interesse manifestados pelos estudantes podem ser ponto de partida para a organização e seleção dos conteúdos matemáticos? Como conceber práticas de ensino que instrumentalizem os estudantes a problematizar questões socialmente relevantes para si? Em que medida as práticas de ensino podem conceber os estudantes como produtores do currículo de Matemática?

Essas questões, e outras que poderiam ser elaboradas, ajudam a pensar sobre o 
currículo e o papel da escola na formação de crianças, jovens, adolescentes e adultos e são pertinentes para se pensar no sentido de currículo estudado na formação inicial e constituidor da identidade profissional docente.

No contexto das práticas de ensino de Matemática nos ensinos Fundamental e Médio, o currículo se organiza por disciplina, as quais reúnem o conhecimento em áreas de especialidade. No entendimento de Beane (2003), essa organização leva os estudantes a construir uma representação social do conhecimento como sendo fragmentado, possível de estudo por uma determinada disciplina escolar, representativa da elevada cultura acadêmica.

Essa forma de organizar o conhecimento que precisa ser construído nos espaços de aprendizagem, sejam eles escolares ou não, remete à proposta de formação técnica, conteudista, cumulativa e preparatória para etapas posteriores de ensino. Desse modo, o sentido de ensinar e aprender determinado conteúdo é a preparação para trabalhar outros mais complexos. Como temos discutido, trata-se de proposta de educação ancorada na racionalidade técnica, em que a aprendizagem ocorre pela linearidade do conhecimento, tendo como objetivo a formação de mão de obra especializada para atender a lógica do mercado de trabalho (JANUARIO; LIMA; PEROVANO, 2020). O processo educacional, implicado por essa lógica, detém o controle do que é ensinado e aprendido a partir de orientações e lista de conteúdos e objetivos prescritos em documentos curriculares.

Tendo a disciplinaridade como organização do conhecimento, o currículo expressa a manutenção do status quo educacional, em que os conteúdos são determinados por instâncias externas à escola, geralmente por especialistas que poucos conhecem da realidade do entorno da escola e dos problemas aos quais ela está imersa ou, ainda, daquilo que os estudantes demandam como interesse de estudo, análise e compreensão. Para Silva (1999), concebido como estrutura da massificação da sociedade, o currículo disciplinar representa o princípio industrial, para o qual à escola cabe a responsabilidade de formar indivíduos capazes de mobilizar o conhecimento para resolver problemas práticos, sem a necessidade de uma ação de pensamento problematizador.

Sendo disciplinar, o currículo tradicional tem no professor o representante do conhecimento formal, produzido como herança cultural, responsável pela formação que padroniza as aprendizagens dos estudantes a partir da organização e seleção de conteúdos previamente planejados por especialistas externos à realidade da escola. No entendimento de Zabala (1998), adversas às questões sociais, as práticas de ensino conduzem a saberes unitários, desconectados e dispersos.

A Matemática, como disciplina escolar, é um dos dispositivos de poder, que fornece ferramentas para controlar a uniformização do conhecimento dos estudantes, a partir da organização, seleção, abordagem e tratamento dos conteúdos. A linearidade é a opção de organização dos conteúdos no currículo tradicional, para a qual o conhecimento se dá por meio de acúmulo e sucessão de abordagem dos conteúdos, geralmente, de menor para maior grau de complexidade; cada conteúdo é pré-requisito para a aprendizagem de outros novos. No desenvolvimento do currículo tradicional, disciplinar, servir de base para conhecimentos mais elaborados é a justificativa para a organização linear, a qual não permite flexibilidade nas práticas de ensino.

Práticas de ensino que partem dos conhecimentos dos estudantes, do que demandam como necessidade de aprendizagem, e colocam a Matemática a serviço da problematização de questões sociais transcendem o currículo disciplinar. Na concepção de Beane (2003), esse 
currículo se apresenta como desafio à imaginação dos estudantes, possibilitando a relação entre escola e vida real, o que possibilita a compreensão dos indivíduos sobre si e sobre o mundo onde vivem. Nessa lógica do currículo, o conhecimento assume importância imediata de questões que despertam o interesse dos estudantes, e se configura como sendo integrador de diferentes conhecimentos, para além de uma determinada disciplina (SILVA, 1999).

A abordagem daquilo que é interesse de compreensão e que se configura como um problema real ou questão a ser analisada, permite motivação do estudante, levando-o a estabelecer relações e a dar sentido e significado ao que se aprende, estimulando compreensões mais amplas, como destaca Alonso (2002).

Se o conhecimento é produzido historicamente pelos indivíduos implicados em um mundo social, cultural e político, ele é dinâmico e pode originar o currículo concebido a partir de práticas e experiências daqueles que fazem a realidade escolar - professores, estudantes, equipe gestora e comunidade (JANUARIO; LIMA; PEROVANO, 2020). Para além de algo estático, desconexo da realidade da qual a escola está inserida, o currículo pode ser compreendido como discurso atravessado de experiências, curiosidades, interesses, questões sociais e problemas que requerem sua exploração para se produzir um processo de compreensão.

No entendimento de Beane (2003), as práticas de ensino baseadas na lógica da integração curricular têm os problemas significativos aos estudantes, e à comunidade escolar, como centros organizadores das aprendizagens, ligando a escola com o mundo em geral; o contexto para unificar o conhecimento são centros organizadores. A integração envolve professores e estudantes na investigação de temas e problemas, o que necessita de conhecimentos articulados de diferentes disciplinas (ALONSO, 2002).

Na perspectiva progressista de educação, o currículo integrador se utiliza de práticas que reconhecem o papel da escola na formação de estudantes conscientes da necessidade de produção de uma sociedade menos desigual, na defesa e manutenção do estado democrático de direito. A Matemática, como disciplina escolar, colabora para esse processo fornecendo ferramentas (conteúdos) e se configurando como linguagem para a compreensão de problemas e proposição de alternativas de práticas sociais inclusivas, eticamente implicadas com o bem-estar comum.

A integração curricular não nega o conhecimento culturalmente construído pela humanidade, pelo contrário, utiliza-se dele para problematizar questões globais que implicam problemas locais. Esse conhecimento, prescrito em documentos que procuram padronizar as experiências formativas, é o meio para se chegar a elaboradas compreensões do que somos, onde estamos, onde queremos chegar e porque precisamos alcançar níveis mais elevados de conhecimento.

Estando o currículo a serviço da problematização de questões sociais, a organização dos conteúdos segue uma lógica rizomática (JANUARIO; LIMA; PEROVANO, 2020), possibilitando aprendizagens como rede de significados. Como um rizoma, o currículo de Matemática organiza os conteúdos como conhecimentos subjacentes nos temas de interesse demandados pelos estudantes; cada conteúdo pode ser representado por um ponto que dá origem a outros, todos relacionados entre si, por distintas incidências sem privilégio ou grau de importância. Todos os conteúdos são relevantes para a compreensão de problemas pessoais ou sociais dos estudantes.

O currículo integrador considera a experiência de vida dos estudantes, o contexto 
social onde a escola está inserida, os problemas globais. Sua planificação se dá de modo colaborativo entre professores e estudantes, desenvolvido conjuntamente com a finalidade de uma formação integral dos indivíduos implicados pela escola; valoriza estratégias de ensino diversificadas e ativas; rompe com a lógica disciplinar, permitindo a construção de conhecimento integrado a diferentes disciplinas. No currículo integrador, professor e estudantes são compreendidos como produtores de conhecimento.

A vasta literatura sobre formação de professores que ensinam Matemática tem indicado o papel desafiador desses profissionais nas práticas de ensino que possibilitem processos de aprendizagem socialmente contextualizados, politicamente reflexivas, eticamente inclusivas, promotores do pensamento crítico sobre o papel de cada indivíduo na construção de uma sociedade menos desigual e mais justa. A literatura tem indicado os professores como produtores de cultura e de currículo, como intelectuais que mobilizam seus conhecimentos para a ação transformadora (GIROUX, 1997). O nosso entendimento, como formadores de professores, é que se temos como princípio o desenvolvimento curricular que promova uma formação integral dos estudantes, precisa-se oportunizar experiências formativas aos professores em formação para conhecer, vivenciar e pensar possibilidades de se romper com a prática de currículo que uniformiza e restringe a criatividade matemática dos estudantes, limitando suas aprendizagens.

Ao perseguir esse princípio, foi proposta uma experiência a uma turma de Pedagogia, que envolvia o estudo e concepção de um projeto integrador, tendo a Matemática como uma das disciplinas que colabora para o seu processo formativo e para as práticas de ensinar e aprender nos Anos Iniciais do Ensino Fundamental. Na sequência, passaremos a apresentar essa experiência.

\section{Contextualizando a proposta de currículo integrador}

No primeiro semestre de 2020 foi ofertada a disciplina Ensino e Aprendizagem de Matemática IV, cuja docência foi de nossa responsabilidade, no curso Licenciatura em Pedagogia do Centro de Educação Aberta e a Distância da Universidade Federal de Ouro Preto. Essa disciplina correspondia a 4 créditos, ou seja, 72 horas/aula, e a turma era constituída de sete polos, com 101 estudantes matriculadas, sendo a sua maioria do gênero feminino².

A ementa contemplava temas relativos a documentos curriculares de Matemática, especificamente, o estudo de orientações de ensino, a organização dos conteúdos, estratégias e recursos metodológicos, análise de materiais curriculares e integração das atividades curriculares. Esses temas foram organizados em quatro unidades, sendo a integração curricular abordado na terceira unidade, além de constituir o fio condutor das discussões durante toda a disciplina.

Três textos foram as principais referências para a discussão sobre integração curricular, quais sejam, Integração curricular: a essência de uma escola democrática, de autoria de James Aires Beane; Integração curricular e interdisciplinaridade: sinônimos?, de autoria de Joanez Aparecida Aires; e Transgressão e mudança na Educação: os projetos de trabalho, de autoria de Fernando Hernández. Além de leitura e discussão nas aulas síncronas, foram propostas duas atividades contínuas tendo a integração curricular como eixo organizativo do currículo

\footnotetext{
${ }^{2}$ A partir desse ponto será usado o gênero feminino em referência aos estudantes e às estudantes que cursaram a disciplina.
} 
de Matemática: a elaboração de um plano de aula e a elaboração de uma ficha de avaliação de materiais curriculares. Para a atividade avaliativa final foi proposto a concepção de um projeto de ensino de Matemática conforme o entendimento de Hernández (1998), considerando a integração curricular, ou seja, projeto cujo tema emerge de problemas sociais, manifestado pelos estudantes como relevante para compreensão.

Um modelo ${ }^{3}$ de estruturação da atividade foi elaborado e disponibilizado à turma. Esse modelo contemplava a apresentação do grupo de estudantes (nome dos participantes e suas habilidades, características do grupo); a realidade local onde o grupo de estudantes estava inserido; a descrição dos desafios (problemas, causas e o que poderia ser feito); plano de desenvolvimento do projeto (resultados esperados, atividades, recursos necessários, responsáveis e cronograma, avaliação e resultados); avaliação do projeto; aprendizagens com a experiência de problematização e compreensão do tema abordado. A composição do grupo de estudantes, isto é, alunos de uma turma dos Anos Iniciais do Ensino Fundamental, sua descrição e as atividades correspondentes a cada um foi uma elaboração hipotética, uma vez que as licenciandas ainda não atuavam como professoras. Os demais itens da atividade correspondem a aspectos sociais vivenciados pelas licenciandas, em especial, os problemas levantados.

Tomando como referência os estudos de Hernández (1998), a proposta consistiu em levar as licenciandas a experienciar o levantamento de problemas sociais da localidade onde a escola e seus estudantes poderiam estar inseridos; levá-las a vivenciar o trabalho em pequenos grupos, consultar fontes diversas, conceber o conhecimento em função da pesquisa e se perceber como professoras que coordenam as aprendizagens dos estudantes. O objetivo da atividade foi o de dar condições para que as licenciandas concebessem a Matemática como uma disciplina que colabora para a problematização de questões sociais e para a construção de conhecimento integrador entre diferentes disciplinas, identificando conteúdos, estratégias metodológicas, formas de acompanhamento e avaliação adequadas ao trabalho com projetos.

Do total de licenciandas matriculadas na disciplina (101), 87 fizeram a atividade em pequenos grupos (duplas ou trios) ou individualmente, resultando em 39 atividades, quais sejam, 39 concepções de projeto integrador. Esse conjunto de atividades é objeto de análise e discussão da próxima seção, sendo mencionados como PJ01, PJ02, ..., PJ38, PJ39, e resguardado o anonimato das licenciadas autoras.

O detalhamento dos procedimentos metodológicos, com vistas a problematizar o desenvolvimento curricular em Matemática a partir de projetos integradores como prática na formação inicial de professores, direciona para um estudo de abordagem qualitativa e do tipo análise documental. Denzin e Lincoln (2006) nos ajudam a entender que essa abordagem e esse tipo se mostram os mais adequados por considerar, inicialmente, as subjetividades daquele que se debruça sobre um conjunto de dados para compreender um determinado fenômeno (desenvolvimento curricular em Matemática) tomando como objeto um conjunto de documentos (projetos integradores), os quais expressam propostas de ensino de

\footnotetext{
3 Esse modelo foi baseado no Plano de Ação Comunitária (PLA) do Programa Nacional de Inclusão de Jovens (ProJovem Urbano). Esse programa foi concebido pela Secretaria Nacional da Juventude, órgão da SecretariaGeral da Presidência da República, apreciado e aprovado pelo Parecer CNE/CEB no 18/2008. O PLA compreende o mapeamento de desafios, problemas sociais, da comunidade onde os jovens estão inseridos, o que requer o conhecimento da realidade social e local da cidade, com vistas ao desenvolvimento de ações de formação e qualificação profissional, objetivando a participação cidadã.
} 
Matemática, carregadas de sentidos e significados a partir de problemas apresentados por indivíduas (licenciandas em Pedagogia) política e socialmente implicadas na realidade local. Passaremos a análise e discussão.

\section{Projetos integradores como indutores da prática de ensino em Matemática}

Como modalidade organizativa do currículo integrador, os projetos são recursos metodológicos nos quais os conteúdos estão centrados em temas de interesse dos estudantes ou problemas sociais da realidade local. O ponto de partida de sua concepção está nos temas ou problemas, juntamente com perguntas e pesquisa, ao invés da definição de conceitos e objetivos de ensino. Esses aspectos, no entender de Hernández (1998), Alonso (2002) e Beane (2003), é o que possibilitará romper com as barreiras das disciplinas, implicando atividades práticas que requerem conhecimentos de diferentes áreas.

A busca por respostas ao problema identificado ou por compreensão de um tema demandado leva à necessidade de estratégias de visitas técnicas, exploração de fontes documentais, levantamento de informações com pessoas ou em instituições, organização e seleção de informações, o que é próprio de trabalho em grupo. Em equipe, negocia-se e define o tema ou problema, inicia-se um novo processo de pesquisa e a busca refinada de informações; critérios são estabelecidos para a ordenação, interpretação e discussão das informações; dúvidas e perguntas conduzem à relação com outros problemas; elabora-se respostas e compreensões, seguida da avaliação do que aprendeu no processo, o que pode implicar a elaboração de outros problemas que serão ponto de partida para novas aprendizagens (HERNÁNDEZ, 1998).

$\mathrm{Na}$ atividade proposta às licenciandas, o ponto de partida foi compor, hipoteticamente, o grupo de estudantes, descrevendo suas características e habilidades, como passaremos a destacar.

\subsection{Os estudantes, suas características e habilidades}

Em um contexto real de sala de aula, conhecer os estudantes, suas características e habilidades é importante para planejar diferentes tarefas que poderão ser demandadas no desenvolvimento do projeto de ensino. Do ponto de vista dos estudantes, conhecer as dificuldades e habilidades de cada participante do grupo é relevante para o planejamento de diferentes ações e a distribuição de tarefas. Para Hernández (1998), o trabalho com projetos é propício para a aproximação da identidade dos estudantes e para o conhecimento de suas potencialidades.

Do conjunto de 39 projetos, as licenciandas autoras de 38 deles caracterizam os grupos de estudantes considerando, em média, 5 participantes em cada um; em um projeto de autoria individual o grupo foi constituído pela própria licencianda. Esse número (5) parece um quantitativo razoável para o trabalho em equipe, principalmente considerando as tarefas que um projeto pode demandar; para a professora da turma, esse também é um número que facilita a organização de seu trabalho. Considerando que, em média, uma turma é composta de 35 estudantes, reduzir para sete a coordenação de tarefas e das aprendizagens possibilita à professora acompanhar melhor os estudantes, identificar pontos que requer maior intervenção, observar as estratégias delineadas por eles para desenvolver as tarefas, e conhecer o processo de aprendizagem de cada um. 
No entendimento de Hernández (1998), ao trabalhar com projetos, predomina-se a atitude de cooperação entre os estudantes e entre estudantes e professora; ambos mobilizam e compartilham o que sabem e, pela discussão, procuram consensuar os entendimentos. A organização em número reduzido permite que, no grupo, todos possam trazer suas impressões, a dar suas opiniões, a distribuir tarefas e a desenvolver a discussão que levará a conclusões e a novos problemas. Nesse processo, a professora também se coloca na situação de quem aprende, rompendo com a lógica de uma profissional técnica e representante do conhecimento produzido e herdade culturalmente (BEANE, 2003).

Quanto às características gerais do grupo, a descrição nos 39 projetos converge para diferentes aspectos. Parte das licenciandas destacaram a diversidade e o engajamento dos integrantes do grupo. Da leitura atenta das descrições, destacamos alguns excertos que ilustram as caracterizações: "dominam bem os conteúdos, são atentos e curiosos" (PJ01); "cada um com as suas habilidades será capaz de contribuir de maneira significativa na construção do projeto" (PJ02); "turma muito comprometida e se envolve com muita responsabilidade em qualquer atividade e projeto proposto" (PJ04); "o grupo é muito comunicativo, curioso" (PJ05); "o grupo possui facilidade para interagir, possui uma boa capacidade de concentração e estão aprendendo a tomar decisões" (PJ06); "são alunos bem responsáveis, comprometidos e criativos, que gostam de participar de eventos escolares e conseguem desempenhar com êxito atividades em equipe" (PJ12); "são alfabetizados, inteligentes, todos empenhados em aprender o conteúdo" (PJ14); "com ideias inovadoras" (PJ17); "autônomos, que normalmente são questionadores" (PJ19); "as crianças possuem facilidade para realizar trabalhos em grupos e apresentações para o público" (PJ23); "preocupados com assuntos relacionados ao consumo consciente" (PJ28); "alguns com habilidades em produções manuais" (PJ36); "apresentam excelente participação nas atividades propostas, boa desenvoltura nas apresentações" (PJ37); "reúne alunos dedicados aos estudos, cada um com suas características individuais se esforçam ao máximo para realização de atividades propostas" (PJ38).

Como é possível observar, hipoteticamente boa parte dos grupos é constituída de estudantes envolvidos, participativos, comunicativos, curiosos, responsáveis e dedicados. Essa forma em descrevê-los, ressaltando aspectos positivos, pode ser fruto da idealização das licenciandas do que seja uma turma ideal para se trabalhar com projetos. Reflete o discurso de alguns professores quando convidados a adotar estratégias diferenciadas no desenvolvimento curricular, principalmente situações em que os estudantes são os autores de suas aprendizagens e agentes de seu percurso formativo. A projeção daquilo que seja ideal pode ser um elemento dificultador para se experienciar inovações curriculares, principalmente nas aulas de Matemática, disciplina que, historicamente, reúne discursos permeados de elementos que levam à adoção de práticas centradas na reprodução de procedimentos e com pouca abertura para um processo criativo pelos estudantes, como discutido por Masola e Allevato (2019).

No âmbito dessa idealização, estão as descrições referentes à alfabetização dos estudantes, como fator ilustrativo da facilidade de se trabalhar com projetos, por exemplo, "dominam bem os conteúdos" (PJ01); "todos alfabetizados" (PJ08); "grupo alfabetizado" (PJ10); "elevado nível de alfabetização e letramento em Matemática e Português" (PJ15); "crianças alfabetizadas que demonstram aptidão para interpretação de textos e imagens" (PJ16); "são todos alfabetizados e apresentam ideias criativas, além do esperado e soluções 
inovadoras nas aulas de Matemática" (PJ24); "alunos já alfabetizados; dominam a leitura e escrita" (PJ37). Certamente, o fato de serem alfabetizadas e letradas facilita as práticas de ensino e favorece a implementação de inovações curriculares. No entanto, é preciso ter consciência que pensar em inovações para crianças que ainda precisam avançar na leitura e escrita é um desafio e compromisso dos professores ao desenvolver o currículo e criar as condições para que as aprendizagens matemáticas ocorram.

Ao focar a diversidade presente nos grupos, algumas descrições convergem para aspectos que, embora sejam potencializadores para o trabalho com projetos integradores, constituem-se como desafio para as práticas de ensino, por exemplo, "moram em bairros diferentes do município (alguns chegam na escola utilizando o Rota Escolar) o que contribuirá para a análise da situação apresentada em diferentes realidades" (PJ02); "pertencem a uma comunidade onde a maioria dos pais são de baixa renda" (PJ12); "os grupos foram divididos quanto a regionalidade. Estes alunos moram em uma comunidade carente longe do centro urbano" (PJ18); "são crianças de uma classe econômica e social baixas, com pouco acesso a bens de consumo e os serviços são os essenciais" (PJ21); "todos residem próximos, no mesmo bairro e, portanto sofrem influências comuns de aspectos sociais" (PJ32).

Hernández (1998) nos ajuda a entender que, para esses grupos, ao desenvolver o projeto, o percurso de aprendizagem favorece a análise de problemas sociais, possibilita a análise e interpretação crítica da realidade local. O desafio se configura nesses aspectos, o que requer da professora intervenções e problematizações que levem os estudantes a se reconhecer como sujeitos de direitos, implicados nesses contextos e agentes do pensamento crítico. Nesse sentido, o currículo integrador permite aos estudantes desafios à sua imaginação, relacionando o que se aprende e discute na escola com a realidade local na qual estão imersos, o que, para Beane (2003), possibilita o aprofundamento e alargamento da compreensão de si e de seu mundo.

Ainda na sintonia dos desafios, em uma quantidade reduzida dos projetos, as licenciandas ressaltaram aspectos que requerem o planejamento atento do trabalho com projetos, por exemplo, ao destacar grupos que "tem aluno que é muito tímido e aluno que é mais desinibido. Alguns gostam de ler e outros gostam de desenhar e de jogos e tem um aluno com necessidade especial" (PJ06); e "composto por alunos com diferentes características no que diz respeito à personalidade" (PJ31).

A descrição das habilidades individuais dos estudantes hipotéticos que integram os grupos converge para os sentidos destacados nos excertos, o que reafirma a forma como as licenciandas idealizam as turmas dos Anos Iniciais do Ensino Fundamental quando do trabalho com projetos que visam à integração dos conhecimentos, considerando a Matemática como uma disciplina que colabora nessa prática de ensino.

\subsection{A realidade local e seus desafios}

Beane (2003) compreende que as experiências e os sentidos e significados atribuídos a partir delas não se configuram como categorias estáticas e limitadas, mas como algo dinâmico e fluido que pode ser organizado para lidar com um determinado tema e outros que derivam deste. Essa dinamicidade e fluidez é o que caracterizam o rompimento da lógica disciplinar, dando lugar à produção de um conhecimento integrado. Hernández (1998), Zabala (1998) e Alonso (2002) discutem que o contexto social onde os indivíduos estão imersos é o cenário do qual emergem questões e problemas que requerem pesquisa, análise e 
compreensão de fenômenos globais que os implicam.

$\mathrm{Na}$ atividade de concepção do projeto integrador, foi proposto que as licenciandas considerassem a realidade local de onde estavam inseridas para que, dela, pudessem emergir os problemas de estudo. Como a maior parte dos projetos é de autoria de um grupo de licenciandas, entende-se que a realidade retratada foi fruto de discussão e consenso.

A leitura das 39 realidades descritas conduz a um conjunto de questões que despertaram o interesse de estudo das licenciandas. No Quadro 1 pode-se observar a categoria dos aspectos apresentados nos projetos integradores, destacando-se realidades relativas a problemas sociais e saúde.

Quadro 1 - Categorização da realidade local.

\begin{tabular}{|c|c|}
\hline Projeto & Categoria do Aspecto da Realidade \\
\hline PJ14, PJ22, PJ35 & Educação \\
\hline PJ09, PJ23, PJ25 & Políticas Públicas Educacionais \\
\hline $\begin{array}{r}\text { PJ02, PJ06, PJ08, PJ10, PJ11, PJ12, PJ13, PJ17, } \\
\text { PJ20, PJ30, PJ34, PJ36 }\end{array}$ & Poluição \\
\hline $\begin{array}{r}\text { PJ04, PJ05, PJ18, PJ21, PJ24, PJ26, PJ27, PJ28, } \\
\text { PJ29, PJ31, PJ32, PJ33, PJ37, PJ38, PJ39 }\end{array}$ & Problema Social \\
\hline PJ01, PJ03, PJ07, PJ15, PJ16, PJ19 & Saúde \\
\hline
\end{tabular}

Fonte: Dados do Estudo.

Esses aspectos, além de serem da realidade local das licenciandas, representam o que Alonso (2002) e Beane (2003) destacam como sendo o que despertam o interesse e provocam a um processo de pesquisa, problematização e compreensão. Para as licenciandas autoras dos projetos integradores, esses aspectos não caracterizam apenas o entorno da escola, de suas residências ou da localidade onde moram os estudantes (hipotéticos), indicam problemas reais que dão forma ao currículo, direciona-o e requerem estudo para sua compreensão e elaboração de respostas como solução.

A adaptação da professora à realidade da escola e ao contexto da turma (PJ14); o quantitativo de estudantes surdos matriculados em escolas, a ausência de recursos metodológicos e financeiros (PJ22); e a realidade social dos estudantes, a falta de acompanhamento dos pais de alguns deles (PJ35), categorizadas como Educação, são questões desafiadoras não apenas para os estudantes, mas para as professoras e a equipe gestora da escola, como é o exemplo do aspecto retratado em PJ14.

O contexto social no qual a comunidade escolar está imersa é cenário que requer atenção e estudo em busca de elaboração de compreensão e alternativas para minimizar problemas enfrentados, sobretudo, pelos estudantes e seus familiares. Categorizados como Políticas Públicas Educacionais, o bairro de classe baixa e seus desafios, onde estão inseridos os estudantes e escola (PJ09), as condições precárias da estrutura física da única biblioteca pública da cidade, o número reduzido de títulos disponíveis (PJ23) e o fechamento de uma biblioteca pública (PJ25) são aspectos destacados em três projetos. Para as licenciandas, as condições precárias do bairro e a falta de espaço público que oportunize o contato com a leitura e pesquisa fora do ambiente escolar são fatores que requerem ações das gestões municipais e, como tema do currículo nas aulas de Matemática, podem desencadear estudo, 
discussão e aprendizagens significativas de conteúdos e de ações de melhoria para os aspectos retratados.

Como temos discutido, o currículo organizado a partir de temas de interesse dos estudantes e da comunidade escolar torna-se significativo e permite colocar a Matemática a serviço da pesquisa e análise de problemas que fazem sentido para quem aprende; os conteúdos e conceitos colaboram para a compreensão da realidade e do levantamento de possibilidades de resolução (JANUARIO; LIMA; PEROVANO, 2020). Nesse sentido, aspectos caracterizados como Poluição foram apresentados nos projetos como sendo temas possíveis de delinear o desenvolvimento curricular, a saber, o córrego poluído com curso dentro da cidade e a necessidade de sua conservação (PJ08); a ausência de coleta seletiva e reciclagem (PJ30, PJ34), bem como a sua implementação (PJ10, PJ12, PJ13, PJ20) ou, ainda, o descarte incorreto do lixo (PJ02, PJ06, PJ11, PJ17, PJ36).

Caracterizadas como Problema Social, aspectos como a necessidade de os estudantes ajudar os pais na colheita de café e de outros produtos da agricultura familiar, requer conhecimentos acerca de questões ambientais e mostra-se como desafio para não interferir nas aprendizagens (PJ05, PJ29); a falta de água no bairro (PJ24, PJ38); o crescimento populacional, as ocupações irregulares, o desencadeamento da crise hídrica (PJ21); e as desigualdades sociais vivenciadas pelos estudantes (PJ32, PJ33), a condição de pobreza (PJ26) e a discriminação de pessoas residentes em bairros periféricos (PJ27) são aspectos que atravessam os muros da escola e sinalizam a necessidade de discussão e análise nas aulas de Matemática e outras disciplinas. A esses aspectos, ainda como Problema Social, acrescentase outros, a saber, a falta de planejamento de urbanização do bairro (PJ18) e, em função disso, a necessidade de arborização (PJ37); o cenário pandêmico causado pela Covid-19, o que desencadeou desemprego e vulnerabilidade das famílias de baixa renda (PJ31), a necessidade de fabricação e distribuição de máscaras (PJO3), a desinformação, falta de políticas públicas, perda de parentes, desenvolvimento de outras patologias (PJ07).

Por fim, categorizadas como Saúde, destacam-se aspectos como a proliferação de outras doenças infectocontagiosas, como a dengue, em resposta ao descarte incorreto de lixo e falta de saneamento básico (PJ01, PJ15, PJ16, PJ19).

A partir das reflexões provocadas por Zabala (1998), Hernández (1998), Alonso (2002) e Beane (2003), entendemos que, ao trazer esse conjunto de aspectos nos projetos integradores de suas autorias, as licenciandas materializam preocupações que impulsionam o desenvolvimento curricular em Matemática reverberando aprendizagens com sentidos e significados aos estudantes. Para elas, esses aspectos constituem-se em cenários dos quais a Matemática pode ser vista como parte da vida dos estudantes, imersa em questões e problemas sociais e que, portanto, pode ser concebida no currículo como instrumento de leitura, interpretação e análise de situações das quais os estudantes estão imersos, colaborando para processos significativos de aprendizagem.

\subsection{A integração curricular}

Pensar a realidade local, identificar aspectos que precisam ser problematizados, caracterizá-los e, a partir deles, elaborar problemas e elencar temas de estudo são o ponto de partida para o trabalho com o desenvolvimento curricular em uma organização integradora, mediado pelo trabalho com projetos de demandas sociais (BEANE, 2003; JANUARIO; LIMA; PEROVANO, 2020). 
Dos aspectos da realidade local descritos nos 39 projetos de autoria das licenciandas em Pedagogia, emergiu um conjunto de problemas e temas que, por sua vez, deram origem a variadas atividades e etapas para desenvolvimento dos projetos. Também foram elencadas possíveis causas e ações que poderiam ser feitas para suas compreensões e, talvez, soluções. Do ponto de vista dos estudantes, descrever esses elementos é uma tarefa importante para o conhecimento dos diferentes problemas, levantamento de suas causas e origem delas, o planejamento de ações, e o desenvolvimento de tarefas.

Após caracterizarem a realidade local, foi solicitado que as licenciandas estruturassem o projeto, descrevendo o seu título, local e foco de desenvolvimento, público-alvo ou problema, justificativa e objetivos. A partir disso, foi solicitado que esquematizassem os temas, conceitos e ou conteúdos que poderiam ser abordados. Por limitação de espaço, passaremos a apresentar algumas propostas que, no nosso entendimento, ilustram o conjunto de projetos elaborados pelas licenciandas.

O foco da realização do projeto PJ08 foi "propor soluções práticas para conservação do Córrego Pamplona, buscando apoio das autoridades locais competentes e das pessoas que moram ao seu redor". A Figura 1 ilustra a esquematização dos temas que emergiram desse problema.

Figura 1 - Temas de estudo do projeto PJ08.

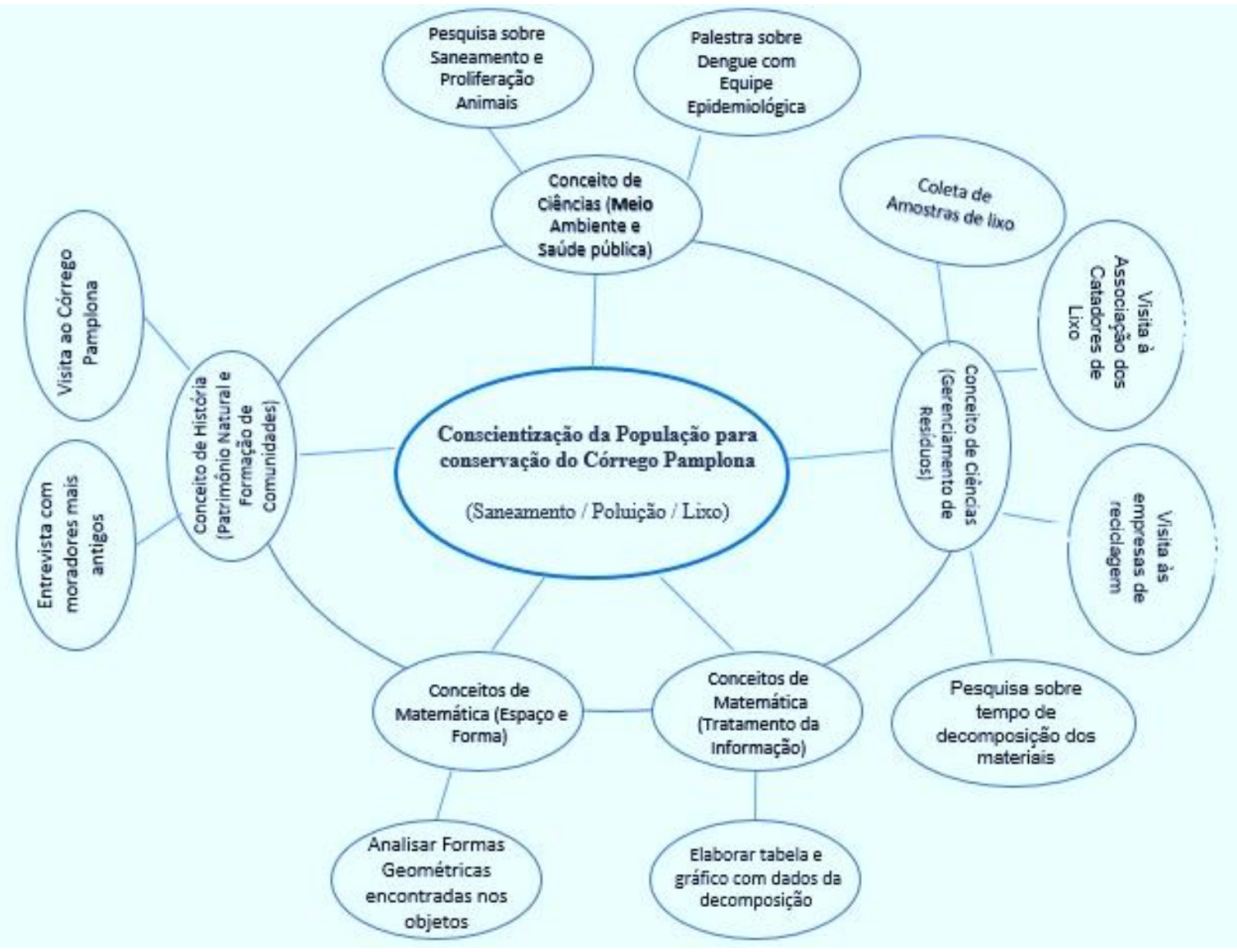

Fonte: Acervo do Estudo (jun. 2020). 
Mobilizar os conteúdos de Matemática, Ciências e História para realizar um trabalho de conscientização dos estudantes em relação ao córrego que corta os bairros da cidade faz com que o currículo rompa com o distanciamento entre o que ocorre na sociedade e o que é abordado nas aulas. A organização de dados relativos ao tempo de decomposição do lixo descartado no córrego em tabelas e gráficos, bem como o estudo de suas formas, cria condições para a análise dos agentes poluentes, impactos no meio ambiente e os problemas que podem causar, como o impedimento do escoamento da água e enchentes, o que levaria à proliferação de doenças infectocontagiosas, por exemplo, a dengue.

O estudo dos conteúdos relativos à Matemática indicados como tema do projeto, em particular, proporciona práticas de ensino que favorecem o desenvolvimento de processos reflexivos e capacidades como base essencial para a problematização e conhecimento de aspectos da realidade local. A Matemática passa a ser vista como disciplina que dá sentido à compreensão de problemas reais, que fazem sentido para os estudantes e, deles, requer tomadas de decisão. Mais que isso, o conhecimento passa a ser construído de modo integrado por meio do estudo de temas (conteúdos) de diferentes disciplinas (ALONSO, 2002; BEANE, 2003). Essa integração foi identificada pelas licenciandas ao estruturar seus projetos, indicando variados temas relacionados aos problemas por elas elaborados, conforme podemos observar no Quadro 2.

Quadro 2 - Temas emergidos do foco de realização dos projetos.

\begin{tabular}{|c|c|c|}
\hline Projeto & Foco da Realização do Projeto & Temas (Conteúdos) \\
\hline PJ01 & $\begin{array}{l}\text { Impactos da dengue na } \\
\text { comunidade escolar e } \\
\text { comunidade do entorno }\end{array}$ & $\begin{array}{c}\text { Matemática (localização e movimentação: representação } \\
\text { de objetos e pontos de referência, unidades de medida); } \\
\text { Geografia (produção, circulação e consumo, interferência } \\
\text { no aproveitamento escolar, proliferação do mosquito } \\
\text { vetor); Português (compreensão e leitura, produção de } \\
\text { texto); Ciências (cadeias alimentares simples, } \\
\text { microrganismos) }\end{array}$ \\
\hline PJ02 & $\begin{array}{l}\text { Redução e a desejável extinção } \\
\text { do descarto incorreto de lixo }\end{array}$ & $\begin{array}{c}\text { Matemática (gráficos, tabelas, unidades de medida); } \\
\text { Linguagens (gêneros textuais, artes visuais, mídias } \\
\text { digitais); Ciências (impactos ambientais, proliferação de } \\
\text { doenças) }\end{array}$ \\
\hline PJ12 & $\begin{array}{l}\text { Buscar inserir a coleta seletiva na } \\
\text { comunidade, diminuir prejuízos } \\
\text { ao meio ambiente e incentivar } \\
\text { atividades de reciclagem que } \\
\text { auxiliem à população em sua } \\
\text { renda familiar }\end{array}$ & $\begin{array}{l}\text { Matemática (matemática financeira, cálculo de medidas, } \\
\text { quantificação de componentes tóxicos e cálculo do tempo } \\
\text { de decomposição); Ciências (meio ambiente) }\end{array}$ \\
\hline PJ13 & Descarte do lixo & $\begin{array}{l}\text { Matemática (geometria, grandezas e medidas, } \\
\text { probabilidade e estatística); Ciências (meio ambiente, } \\
\text { doenças, reciclagem); Geografia (lugar, representação } \\
\text { espacial, relações entre sociedade e natureza); Português } \\
\text { (gênero textual, coerência e coesão dos textos, pesquisas, } \\
\text { leitura e escrita); História (sociedade, moradias, cotidiano, } \\
\text { hábitos e costumes das pessoas, patrimônio) }\end{array}$ \\
\hline PJ16 & $\begin{array}{l}\text { Comunidade situada próxima a } \\
\text { escola que se localiza no bairro, }\end{array}$ & $\begin{array}{l}\text { Matemática (problemas que abordem as operações } \\
\text { básicas determinando o ciclo de vida e a quantidade de }\end{array}$ \\
\hline
\end{tabular}




\begin{tabular}{|c|c|c|}
\hline & $\begin{array}{l}\text { no qual foi encontrado grande } \\
\text { números de larvas da dengue }\end{array}$ & $\begin{array}{c}\text { criadouros do mosquito aedes; levantamento dos } \\
\text { números de casos confirmados de dengue, zica vírus e } \\
\text { chikugunya para trabalhar conceitos de comparação, } \\
\text { proporção e porcentagem); Ciências (doenças } \\
\text { transmitidas e formas de prevenção; fases do } \\
\text { desenvolvimento do mosquito aedes aegypty, ambiente } \\
\text { propício para formação de criadouros); Geografia } \\
\text { (trabalhar a relação do espaço e dos territórios por meio } \\
\text { da elaboração de mapas); Português (linguagem oral: } \\
\text { valores, normas e gêneros discursivos, língua escrita: } \\
\text { prática de produção de textos, leitura, uso e formas); } \\
\text { Artes (elaboração de cartazes, desenhos, pinturas e } \\
\text { teatro) }\end{array}$ \\
\hline PJ21 & $\begin{array}{l}\text { Desenvolvimento de ações para } \\
\text { entendimento do estudante } \\
\text { como autor social, passível dos } \\
\text { problemas em sua relação com a } \\
\text { natureza, na perspectiva de causa } \\
\text { e efeito }\end{array}$ & $\begin{array}{c}\text { Matemática (uso social dos números, porcentagem, } \\
\text { educação financeira, grandezas e medidas, reta numérica, } \\
\text { tabelas e gráficos, sólidos geométricos); Ciências (estado } \\
\text { físico da água, água e a relação com os meios de } \\
\text { produção, propostas sustentáveis para utilização); } \\
\text { Geografia (problemas socioambientais da comunidade } \\
\text { com a água e outros recursos naturais, incentivo à } \\
\text { participação nos órgãos responsáveis pelas políticas } \\
\text { públicas); Língua Portuguesa (leitura, interpretação e } \\
\text { produção de diferentes tipos de gêneros textuais, língua } \\
\text { escrita e verbal) }\end{array}$ \\
\hline PJ31 & $\begin{array}{c}\text { Incentivando o } \\
\text { empreendedorismo e ações para } \\
\text { geração de renda para famílias de } \\
\text { baixa renda, residentes na } \\
\text { periferia de Uberlândia (MG) }\end{array}$ & $\begin{array}{l}\text { Matemática (gestão de negócios, gerenciamento de } \\
\text { recursos financeiros, capacitação e planejamento, } \\
\text { economia); Geografia (visão crítica do meio ambiente, } \\
\text { reaproveitamento da água, reciclagem, coleta seletiva de } \\
\text { lixo); Ciências (meio ambiente, horticultura, pandemia, } \\
\text { hábitos saudáveis, higiene e saúde) }\end{array}$ \\
\hline
\end{tabular}

Fonte: Dados do Estudo

Para Beane (2003), a integração curricular compreende que a escola deve estar a serviço de propósitos e compreensões mais ampla de problemas sociais, os quais atravessam a realidade dos estudantes e o cotidiano da comunidade onde estão inseridos. Essa lógica rompe com o conhecimento linear e com a formação propedêutica, principalmente com aquela cujas práticas de ensino buscam preparar unicamente para uma etapa posterior da escolarização ou a realização de exames. Obviamente que esses aspectos são importantes, mesmo porque fazem parte da sociedade na qual a escola e os estudantes estão inseridos. No entanto, o trabalho com problemas a partir de demandas sociais busca colocar os estudantes como agentes de seu processo de aprendizagem em que a Matemática, e outras disciplinas, além de promover o desenvolvimento de competências específicas dessas áreas, instrumentaliza os estudantes a conhecer sua realidade, problematizá-la, identificar pontos de intervenção e elaborar alternativas para solucionar problemas que afetam suas práticas sociais. Nesse sentido, identificar os temas (conteúdos) é uma ação importante para os estudantes e para as professoras que coordenam o desenvolvimento do projeto (Figura 2). 
Figura 2: Temas de estudo do projeto PJ33

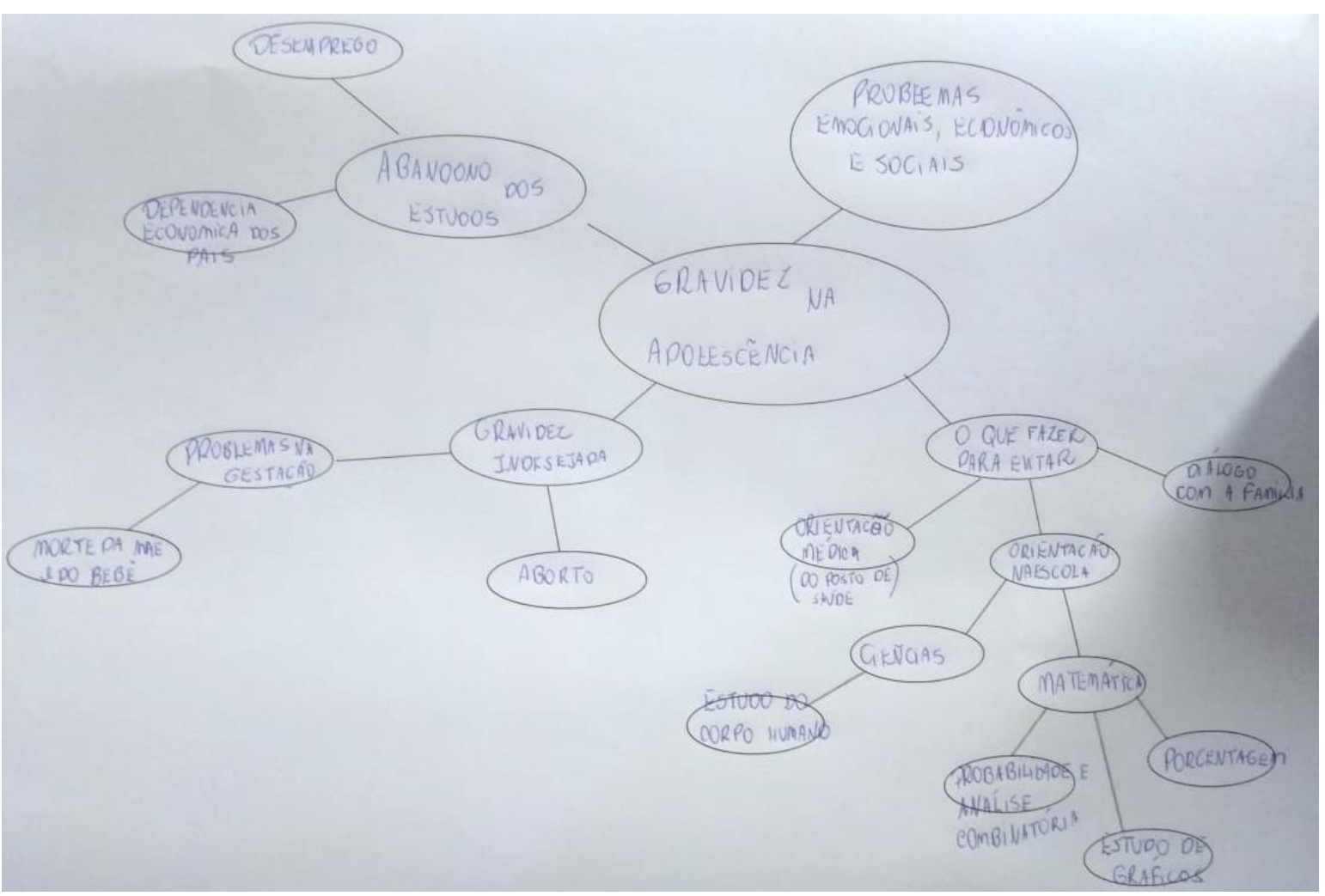

Fonte: Acervo do Estudo (jun. 2020)

A observação da estruturação dos temas levantados nos 39 projetos integradores indica que nem todas as licenciandas destacaram conteúdos específicos de uma determinada disciplina. Em alguns projetos, há a indicação da disciplina relacionada ao problema; em outros, há a indicação de temas amplos. Sobre a Matemática, em particular, em boa parte dos projetos não houve o detalhamento dos conteúdos subjacentes nos problemas, o que pode indicar a necessidade de maior envolvimento com o desenvolvimento do projeto para se perceber os temas que podem ser abordados, ou pode ser a necessidade de maior conhecimento da Matemática, e seus conteúdos, no processo da formação inicial. Nos projetos PJ08 (Figura 1) e PJ33 (Figura 2), esse aspecto pode ser melhor observado.

Como a literatura sobre formação de professores que ensinam Matemática têm amplamente discutido, processos de ensino e de aprendizagem em cursos de formação inicial ainda é um desafio, seja do ponto de vista do currículo, de quem está em formação ou das práticas de ensino. Criar oportunidades de aprendizagem sobre a organização e desenvolvimento curricular em Matemática que rompa com a lógica disciplinar, do conhecimento linear e do professor como única referência para o conhecimento, mostra-se como especial desafio para as práticas de formação.

A partir do que discutem Hernández (1998), Zabala (1998), Alonso (2002) e Beane (2003), o entendimento é que o trabalho com projetos de demandas sociais e, portanto, integradores do currículo, requer dos professores profunda reflexão sobre o processo de planejamento e elaboração do projeto como ferramenta facilitadora da problematização e compreensão do tema abordado; os modos de enxergar e compreender a comunidade na qual a escola, os estudantes e si próprios estão imersos; os principais desafios da participação na 
realização das atividades; o sentido de participação cidadã no cotidiano da sociedade global e local; os direitos de cidadania de todos os indivíduos implicados na/pela escola; sobre quais são as necessidades prioritárias de políticas públicas, programas ou projetos para os estudantes na realidade em que vivem; e sobre o papel da escola, do currículo e da Matemática no desenvolvimento do projeto e na formação dos estudantes.

\section{A vista a partir do horizonte}

Frequentemente, professoras são cobradas para realizar práticas inovadoras no desenvolvimento curricular em Matemática, buscando romper com processos tradicionais de ensino e, com isso, avançar em processos de aprendizagens significativas, situadas nos contextos sociais onde os estudantes e a escola estão inseridos. A literatura que trata da formação inicial tem dedicado parte de suas discussões para problematizar a importância da constituição do conhecimento profissional docente a partir do que a Matemática e a Didática oferecem como suporte para sua instrumentalização.

A abordagem do desenvolvimento curricular em Matemática a partir de projetos integradores como prática na formação inicial de professoras, a partir de sua problematização, constituiu o objetivo de discussão neste artigo, levando à apresentação de uma experiência realizada em uma disciplina do curso Pedagogia, modalidade EaD, da Universidade Federal de Ouro Preto.

A atividade de elaborar projetos integradores levou as licenciandas a pensar na importância de se garantir a diversidade de propostas que podem ser demandadas pelos estudantes; a não subestimar as capacidades deles; a considerar que a construção do conhecimento implicado em questões e problemas da realidade global ou local implica estudo, reorganizações e desconstrução da imagem do professor como único detentor do conhecimento; e a se reconhecer como quem cria condições para que a aprendizagem seja construída, em detrimento de processos de ensino conteudistas.

A discussão aqui feita não tem o propósito de lançar luz à única prática de ensino na formação inicial que oportuniza as licenciandas a refletir sobre o desenvolvimento curricular e romper com a lógica disciplinar da abordagem dos conteúdos de Matemática. Sabemos que muitas alternativas têm sido apresentadas em pesquisas do campo da Educação Matemática, sobretudo aquelas situadas nas linhas de currículos e formação de professores. No entanto, observamos que a experiência de vivenciar a concepção de um projeto a partir de aspectos e problemas sociais da realidade onde os estudantes e a escola estão inseridos mostrou-se potencialmente significativa de um processo de aprendizagem que possibilita a produção de pensamento crítico e a compreensão dos fenômenos atinentes à regionalidade global e local.

Embora considerada por nós como um processo que levou as licenciandas, ou sua maioria, a refletir sobre o currículo de Matemática e alternativas para se criar condições para que os estudantes sejam autores de suas aprendizagens, é importante observarmos se tratar de uma experiência isolada em uma disciplina, no conjunto de outras disciplinas que têm temas e especificidades formativas. Ainda, precisamos considerar que essa experiência também indicou conhecimentos específicos de conteúdos, de abordagem e tratamento didático e metodológico como necessidades de discussão na formação das licenciandas, como o conhecimento de metodologias que podem potencializar o trabalho com projetos, por exemplo, resolução de problemas, modelagem matemática e investigação-exploração nas aulas de Matemática. 
Ao darmos ênfase à importância do estudo do currículo de Matemática, seu desenvolvimento a partir de projetos integradores, também chamamos a atenção para a necessidade do estudo de temas específicos das disciplinas como possibilidade de instrumentalização das licenciandas, futuras professoras, para o planejamento e o desenvolvimento de práticas de ensino inclusivas, integradoras e problematizadoras.

A experiência aqui narrada e analisada limitou-se à elaboração de projeto integrador e, para isso, ao levantamento das demandas sociais das quais poderiam emergir temas e problemas. Cabe salientar que durante o período que a disciplina foi ofertada, março a junho de 2020, a pandemia causada pela Covid-19 levou à necessidade do fechamento das escolas, à adoção de aulas remotas e ao isolamento social. Fora desse contexto, as licenciandas poderiam ter realizado a experiência nas escolas onde atuavam ou realizavam Estágio Supervisionado, além de terem a oportunidade de desenvolver o projeto junto com os estudantes. Certamente, às discussões apresentadas neste artigo acrescentariam outros dados, como a participação dos estudantes e seus processos de envolvimento, descobertas e aprendizagens ao tomar problemas de suas realidades como ponto de partida para se desenvolver o currículo de Matemática. Indicamos esse aspecto como limitador deste estudo, mas, também, como possibilidade de novas investigações.

\section{Referências}

ALONSO, Luísa. Para uma teoria compreensiva sobre integração curricular: o contributo do Projeto PROCUR. Infância e Educação: investigação e práticas, Porto, n. 5, p. 62-88, dez. 2002.

BARBOSA, Cirléia Pereira; LOPES, Celi Espasandin. Um estudo sobre a identidade profissional de futuros professores de Matemática no Estágio Curricular Supervisionado. Educação Matemática Debate, Montes Claros, v. 4, n. 10, p. 1-25, jul. 2020.

BEANE, James Aires. Integração curricular: a essência de uma escola democrática. Currículo sem Fronteiras, v. 3, n. 2, p. 91-110, jul./dez. 2003.

DENZIN, Norman Kent; LINCOLN, Yvonna Sessions. O planejamento da pesquisa qualitativa: teorias e abordagens. Tradução de Sandra Regina Netz. 2. ed. Porto Alegre: Artmed, 2006.

GIROUX, Henry Armand. Os professores como intelectuais: rumo a uma pedagogia crítica da aprendizagem. Tradução de Daniel Bueno. Porto Alegre: Artmed, 1997.

HERNÁNDEZ, Fernando. Transgressão e mudança na educação: os projetos de trabalho. Tradução de Jussara Haubert Rodrigues. Porto Alegre: Artmed, 1998.

JANUARIO, Gilberto. Agência, affordance e a relação professor-materiais curriculares em Educação Matemática. Ensino em Re-Vista, Uberlândia, v. 27, n. 3, p. 1055-1076, set./dez. 2020.

JANUARIO, Gilberto; LIMA, Katia; PEROVANO, Ana Paula. From linearity to rhizomatic network: content organisation in curriculum development in Mathematics. Acta Scientiae, Canoas, v. 23, n. 8, p. 3-22, aug. 2020.

MASOLA, Wilson de Jesus; ALLEVATO, Norma Suely Gomes. Dificuldades de aprendizagem matemática: algumas reflexões. Educação Matemática Debate, Montes Claros, v. 3, n. 7, p. 52-67, 
jan./abr. 2019.

SILVA, Tomaz Tadeu. Documentos de identidade: uma introdução às teorias do currículo. Belo Horizonte: Autêntica, 1999.

SOARES, Marilene Caitano Reis. A relação professor-materiais curriculares de Matemática: análise na perspectiva dos conceitos de affordance e agência. 2020. 142f. Dissertação (Mestrado em Educação) - Centro de Ciências Humanas. Universidade Estadual de Montes Claros. Montes Claros.

STEHLING, Denise França; CONTI, Keli Cristina. Formação continuada de professores, desenvolvimento profissional e conhecimento matemático na Educação Infantil. Educação Matemática Debate, Montes Claros, v. 4, n. 10, p. 1-27, jul. 2020.

ZABALA, Antoni. A prática educativa: como ensinar. Tradução de Ernani Ferreira da Fonseca Rosa. Porto Alegre: Artmed, 1998. 